\title{
الجملة المقيدة بفعل ناسخ بين الاسمية والفعلية
}

Araştırma Makalesi

Yüsrî Abdülfettâh HASEN *

Makale Geliş: 22.10 .2019

Makale Kabul: 05.12.2019

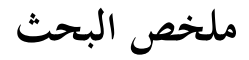

$$
\begin{aligned}
& \text { يتناول هذا البحث موقف النحاة من الجملة المقيدة بفعل ناسخ ( كان وأخواتا )، أهي } \\
& \text { جملة اسمية ، أم جملة فعلية ؟ وتوصلت في هذا البحث إلى أن النحاة لم يصرحوا - على } \\
& \text { ما قرأت - باسمية هذا التركيب أو فعليته، سوى ابن هشام في كتابه " مغني اللبيب " } \\
& \text { صرح بأنه من قبيل الجملة الفعلية. كما توصلت إلى أن بعض النحاة ذهب إلى أن " } \\
& \text { كان وأخواتا “'أفعال ليست حقيق ليقية، وأطلقوا عليها أفعال العبارة } \\
& \text { رصد البحث رأي مَن صرَّح - من المحدثين - بكوُن الجملة المتصدرة بـ "كان " وأخواتما } \\
& \text { جملة اسمية، وهو الدكتور محمد حماسة عبد اللطيف، ذاكرا ما اعتمد عليه في هذا الرأي } \\
& \text { في ثماني نقاط، منها :1- أن ابن جني يرى أنه لا يلزم تأنيث " كان " إذا كان اسمها } \\
& \text { مؤنثا لزوم تأنيث الفعل لفاعله إذا كان مؤنثا أيضا } \\
& \text { رجحت في هذا البحث كون الجملة المتصدرة بفعل ناسخ من قبيل الجملة الاسمية، } \\
& \text { مشترطا وصفها بالمقيدة أو المنسوخة، مضيفا إلى ما قاله د/ محمد حماسة عبد اللطيف ما } \\
& \text { يقوي هذا الترجيح. ومنه: أن الفعل الحقيقي قد يكتفي بفاعله إذا كان لازما، أقول: قام } \\
& \text { الرجل، ونام الطفل .... إلخ. ولا يصح معها هي مثل هذا، فلا يستقيم أن أقول: اليوم } \\
& \text { الجو بارد، أما الأمس فكان الجو...، دون أن أخبر عن طبيعة الجو بالأمس، فأقول مثلا: } \\
& \text { حارًا. } \\
& \text { الكلمات المفتاحية: (المنسوخة - المقيدة - أفعال غير حقيقية - أفعال العبارة) }
\end{aligned}
$$

Nahiv İlmi Açısından Nâsih Fiil ile Kurulan Cümlenin İsim Cümlesi mi Fiil Cümlesi mi Sayılacağı Üzerine Görüşler

$\ddot{O} z$

Bu çalışma, Nahiv İlminde (كان وأخواتها) olarak bilinen nâsih fiillerin, amelleri itibariyle bulundukları cümle üzerindeki fonksiyonlarının cümleyi “isim cümlesi mi” yoksa "fiil cümlesi mi” yaptığına ilişkin Nahiv Bilginlerinin görüş ve tartışmalarını ele almaktadır.

* Dr., Yakın Doğu Ünivesitesi İlahiyat Fakültesi, dr.yousryhasan@gmail.com, ORCID: 0000- 0003- 2208- 5597

Atıf için; Yüsri Abdülfettâh Hasan, "Nahiv Ilmi Açısından Nâsih Fiil ile Kurulan Cümlenin Isim Cümlesi mi Fiil Cümlesi mi Sayılacağı Üzerine Görüşler”, Yakın Doğu Üniversitesi İslam Tetkikleri Merkezi Dergisi, 5, sy. 2 (2019): 413-428, DOI: https://doi.org/10.32955/neu.istem.2019.5.2.06 
Araştırmamızda -görebildiğimiz kadarıyla- Nahivciler bu konuyu tam olarak izah etmemektedirler. Ancak İbn Hişâm, “Muğni’l-Lebîb” adlı eserinde Nâsih fiillerle kurulan cümlenin “fiil cümlesi” olduğuna açıktan vurgu yapar. Oysa Nahiv Bilginleri "Kâne ve kardeşleri' 'nin, öncelikle fiil mi, harf mi oldukları hususunda görüş birliğine varamamışlar, bunların fiil olduğunu savunanların bir kısmı, "zaman bildirdikleri" üzerinde israr ederken, bir kısım nahivci ise, sadece "oluş ve eylem" ifade ettiğini, bazıları da hem "zaman" hem "eylem" bildirdiklerini vurgulayarak ihtilafı sürdürmüşlerdir. Hatta bazıları da, bunların "hakiki manada" fiil olmayıp, "itibari fiil" olduklarını bile dile getirmişlerdir.

Araştırma, -yeni nahivcilerin- ortaklaşa dile getirdikleri "Kâne ve Ahavâtühâ" ile başalayan cümlenin bir “isim cümlesi” olduğuna dair görüş birliklerinin yerinde ve doğru olduğuna dair bir sonuca ulaşmaktadır. Bu konuda özellikle, Aarap Dili Akademisi Üyesi ve Kahire Üniversitesi Sarf-Nahiv ve Urûz İlimleri Fakültesi eski hocalarından Sn. Prof. Dr. Muhammed Hamase Abdüllatif'in konuyu sekiz noktada özetleyen görüşüne yer verilmiştir, ki bizim tercihimizi Muhammed Hamase Amdullatîf' in şu değerlendirmesi güçlendirmektedir:

Lazım fiiller, sadece fail aldıklarından, fiil cümlesi, "fiil ve failden” oluşabilir. Mesela, (نام طفلّ) , gibi cümleler kurabiliriz. Ama nâsih fiil ile kurduğumuz cümlede mutlaka cümlenin haberi olmalıdır. Mesela, (اليومَ الجوُ باردُ) isim cümlesinin başına (كان)

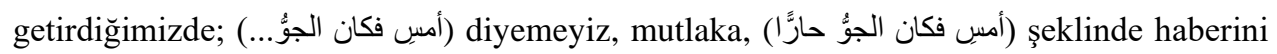
vermemiz gerekir. Zira nâsih fiillerin amelleri, noramal fiiller gibi değildir.

Anahtar Kelimeler: Mensuh, Mukayyede, Gerçek Olmayan Filler, İbare Filleri

The Sentence That Begins With "Kan" and Its Siblings, Whether It Should Be A Noun Phrase or Verb Phrase

\section{Abstract}

This research deals with the grammarians 'opinion about the sentence that begins with "kan" and its siblings, is it a noun phrase or verb phrase? I went on in this research that the grammarians did not declare - as I read - if it is a noun phrase or verb phrase, except Ibn Hisham in his book, "Moghni al Labib" stated that it is a verb phrase .Some of the grammarians also went on to say that they are verbs that are not real, and called them verbs of the phrase.

The research stats a view from one of the modern grammarians who said that the sentence which begins with "kan" and its siblings is a noun phrase, namely, Dr. Mohamed Hamasa Abdullatif, Saying what he relied on in this opinion in eight points.one point is, ibn Genie believed that it is not necessary to feminize "kan" for its name if it was feminine to the need for feminization of the verb for its subject if it was feminine.

In this research, I believe that the sentence that begins with "kan", is a noun phrase, adding to what Mohammed Hamasa Abdul Latif said, which strengthens this opinion as the verb can settle for its subject. We can say: ( qam alrajul, wanam altifl) 'the man stands up.the child has slept'. It is not correct to say: Today the is cold, but yesterday was, without completing the sentence, say, for example: warm .

Key Words: Begin with kan, Noun phrase, Verbs that are not real, Verbs of the phrase 


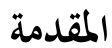

هذا بحث عنوانه " الجملة المقيدة بفعل ناسخ بين الاسمية والفعلية " ، ومن المعلوم أن الجملة الاسمية تتكون من مسند إليه يتمثل في المبتدأ ، ومسند يتمثل في الخبر ، وكلاهما مرفوعان ، ومن المعلوم أيضا أن الجملة الاسمية تتسلط عليها حروف وأفعال ناسخة ، تتمثل الحروف في " إن " وأخواتا ، هذه الحروف تنسخ حكم المبتدأ من الرفع إلى النصب ويسمى اسمها ، ويظل الخبر على حالة الرفع ويسمى خبرها ، وتتمثل الأفعال في "كان " وأخواتها ، و " كاد " وأخواتما ، وعند الحمديث عن الأفعال الناسخة نذكر - عادة - " كان " بكوها أم الباب ، وهذه الأفعال تنسخ حكم الخبر من الرفع إلى النصب ، ويظل المبتدأ على حالة الرفع ويسمى اسمها ـ ومن المعلوم - أيضا - أنه لا خلاف على بقاء الجملة على اسميتها إذا تصدرت بالحروف الناسخة " إن وأخواتا "، لكن الأمر يختلف في تسلط الأفعال الناسخة "كان وأخواتها " - بكوها أم الباب - على الجملة الاسمية، ففيه خلاف كبير، وقد جاء هذا البحث للفصل في هذا الأمر، أعني كون الجملة المبدوءة بفعل ناسخ جملة اسمة أم فعلية؟ أم وقد نقلت أقوال النحاة في اختلافهم في كون "كان " وأخواتحا حروفا أم أفعالا، واختلاف من قالوا بفعليتها في كوها أفعالا حقيقية، أفعالا غير حقيقة . ثم ذكرت في هذا البحث أنه لم يصرح أحد من النحاة بكون هذا التركيب من قبيل الجملة الاسمية أو الفعلية، سوى ابن هشام في كتابه مغني اللبيب ذهب إلى أنه من قبيل الجملة الفعلية.

ثم نقلت رأي بعض المحدثين تمثل في رأي الدكتور محمد حماسة عبد اللطيف؛ حيث ذهب إلى أن

كون الجملة المبدوءة بفعل ناسخ هي جملة اسمية ، مبررا رأيه في ثماني نقاط نقلتها عنه في مكاها . ثم ذكرت ما اطمأن إليه البحث من هذين الابحاهين ، مبررا ما اطمأن إليه البحث ببعض الأمثلة . ويضم البحث العناصر التالية : - -

2- - اختلاف النحاة في كون " كان " وأخواتها أفعالا أم حروفا .اختلافهم في كوها أفعالا حقيقية أم غير حقيقة .

3- - اختلافهم في معموليها من أن اسمها مرفوع بها ، أو أنه مشبه بالفاعل ، وخبرها بالمفعول به أو الحال .... إلخال 4- - رأي الدكتور محمد حماسة عبد اللطيف . . - - مأي الباحث 6 · - - - المصادر والمراجع 


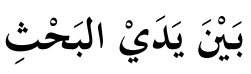

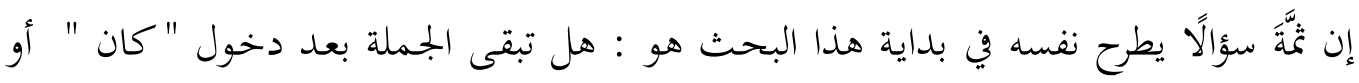

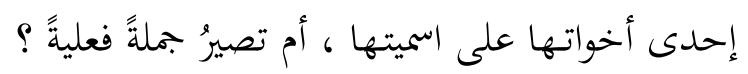

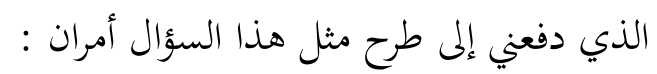

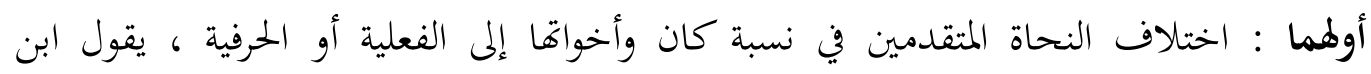

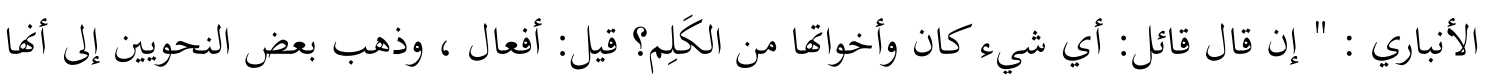

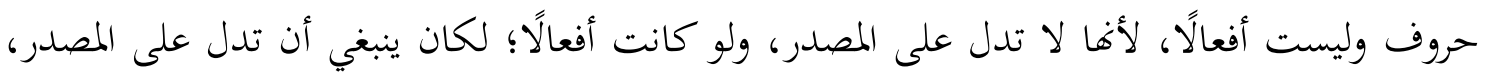

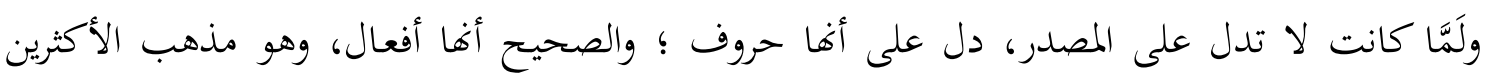

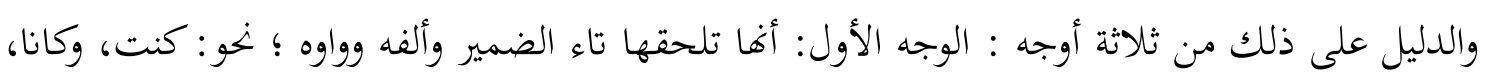

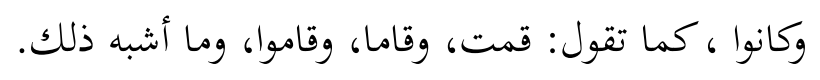

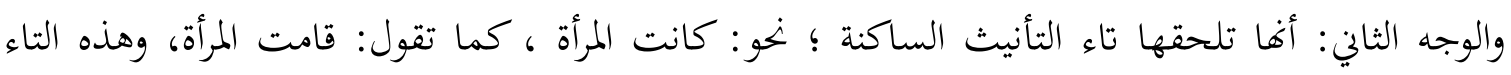

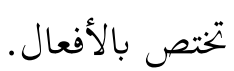

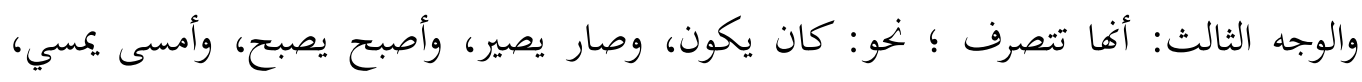

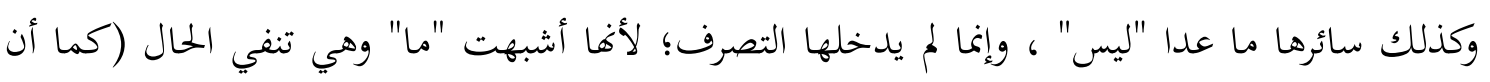

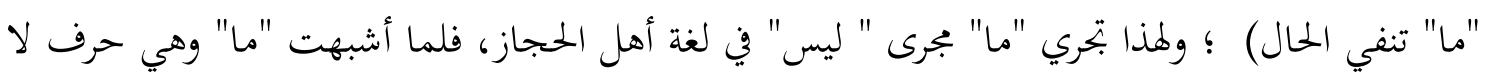

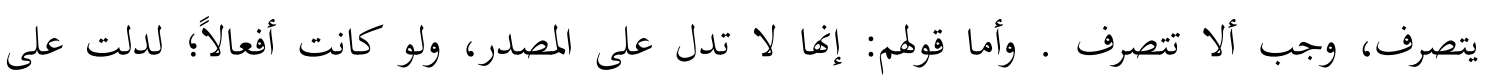

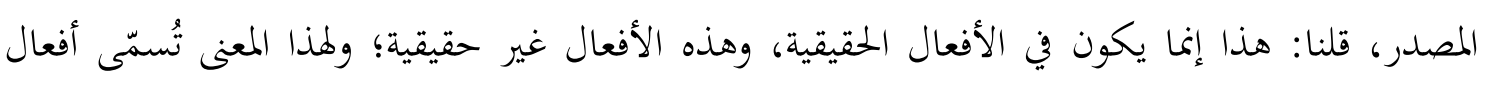

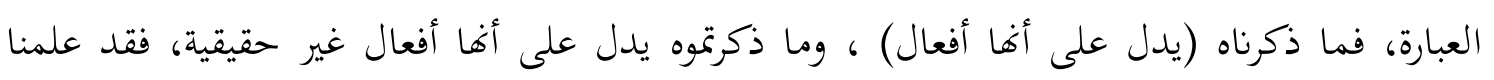

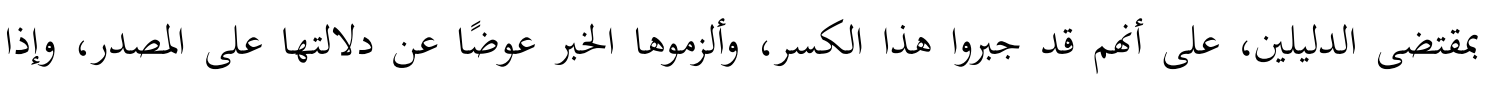

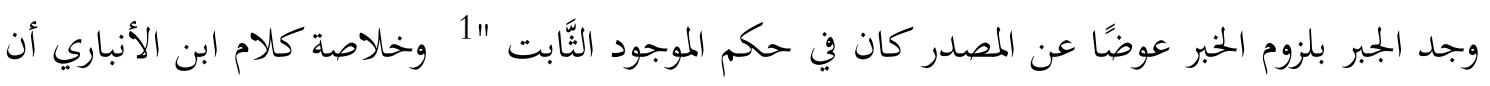

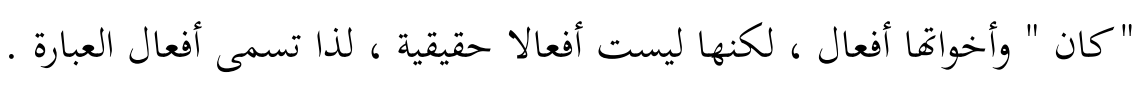

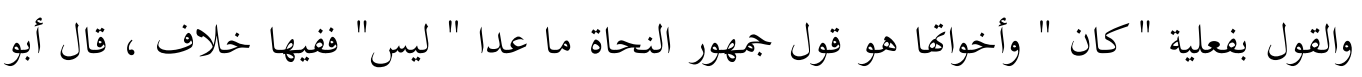

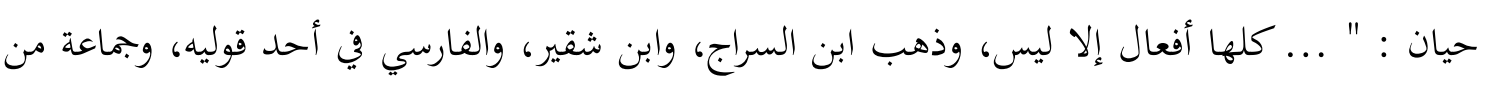

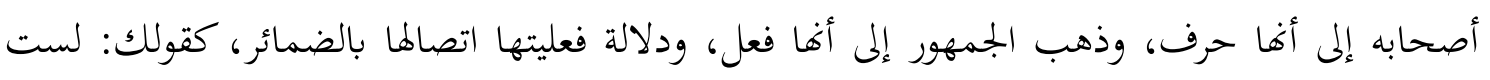

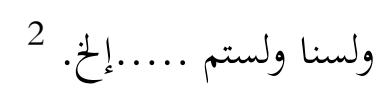

ثم اختلفوا في معمولي هذه الأفعال ، نقل هذا الخلاف أبو حيان ، يقول : " اتفقوا على نصبها

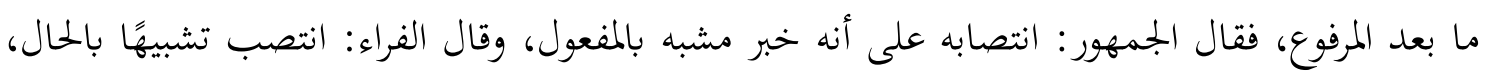

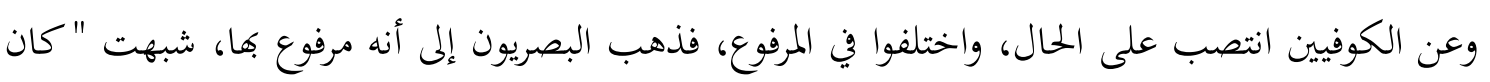

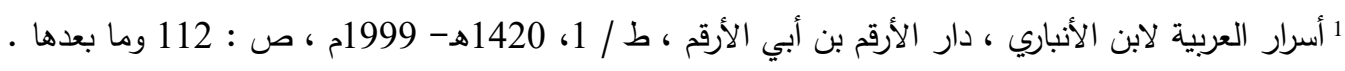
22 ارتثاف الضرب 1146/3 ، ط / 1 ، مكتبة الخانجي بالقاهرة ، وانظر شرح عيون الإعراب لابن لابن فضال ص:105. 
" بالفعل الصحيح نحو: ضرب، فعمل عمله ، وزعم الفراء أنه ارتفع لشبهه بالفاعل، وقال غيره من

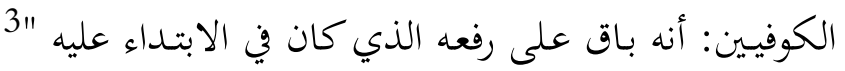

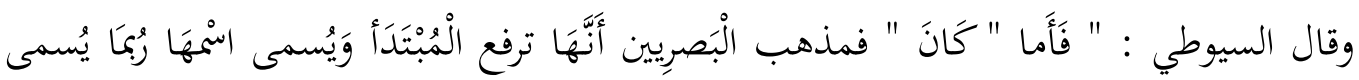

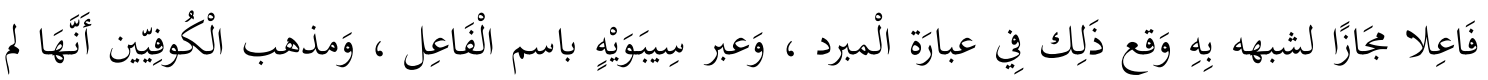

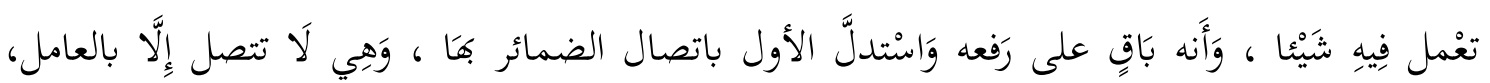

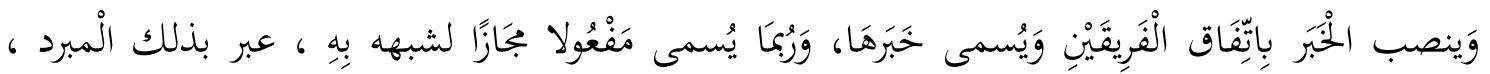

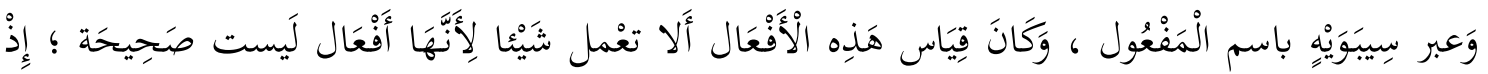

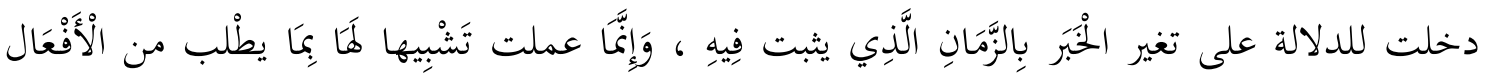

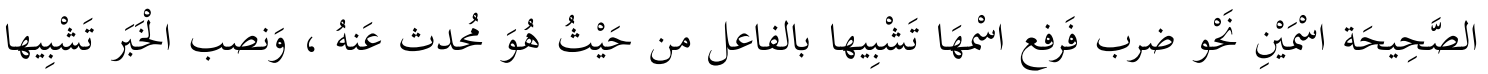

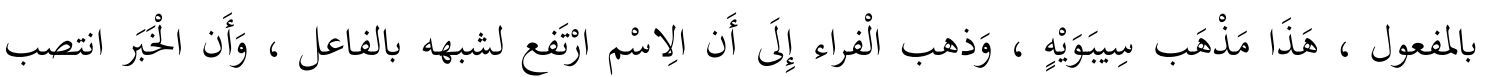

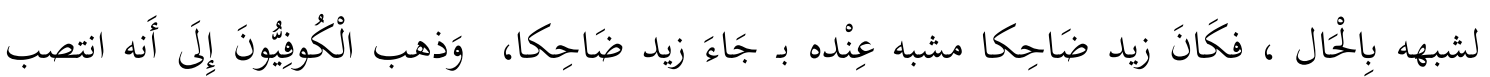

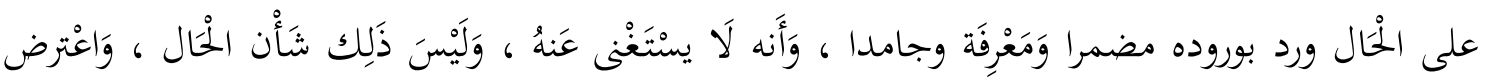

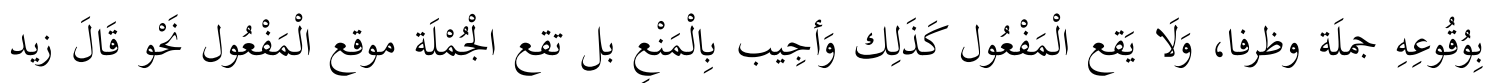

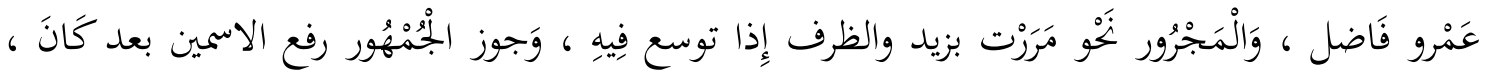
وَأنْكُهُ الْفراء . "

وقال ابن مالك : " الشائع في عرف النحويين التعبير عن مرفوع هذا الباب ومنصوبه باسم وخبر،

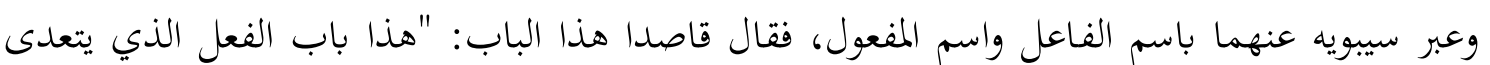

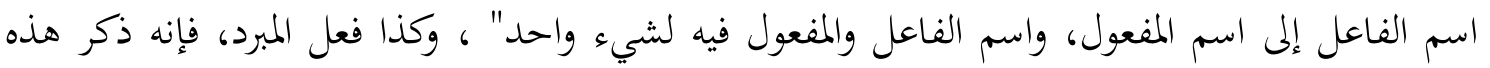

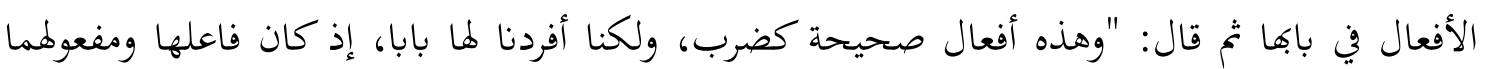

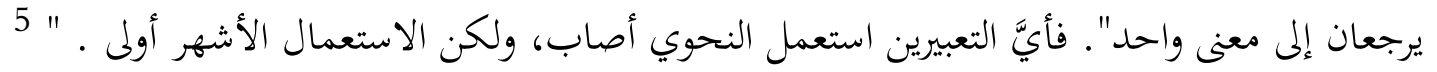

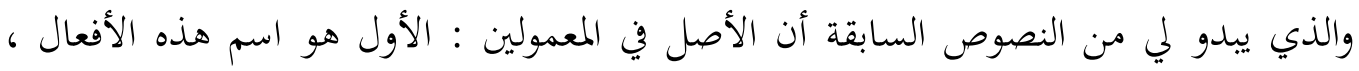

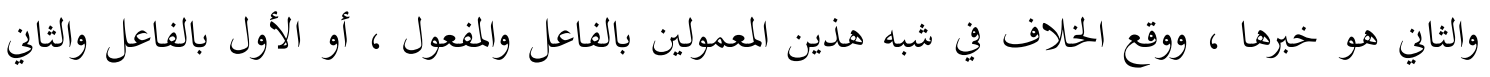

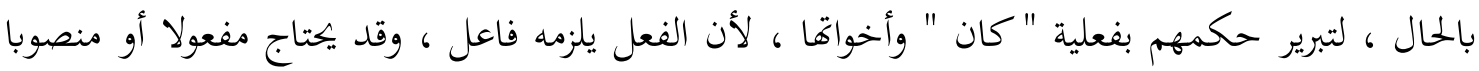

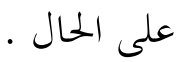

ولم يقف الاختلاف عند الفعلية والحرفية ، أو معمولي هذه الأفعال ، فالذين قالوا بفعليتها اختلفوا

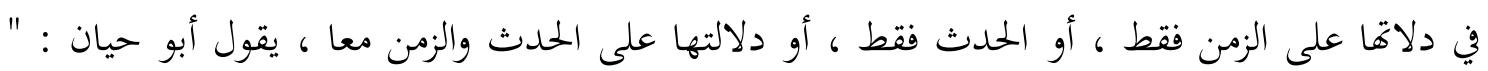

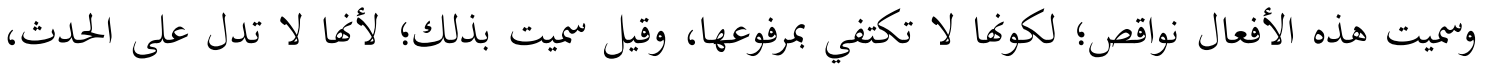

3 ارتشاف الضرب ، 3 | 3146

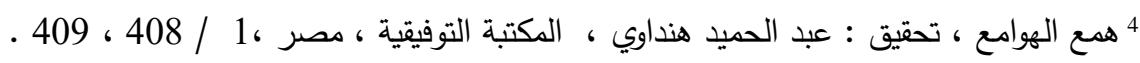

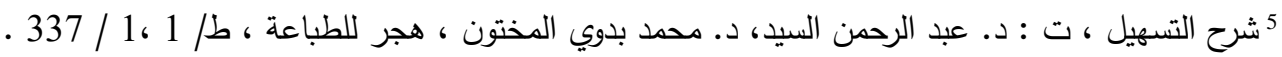


وكوها لا تدل على الحدث فلا تعمل في ظرف، ولا بجرور، وهو مذهب المبرد، وابن السراج، والفارسي،

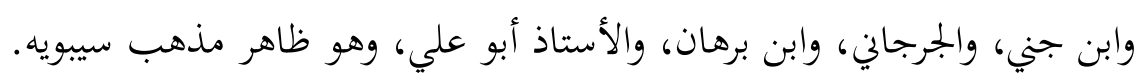

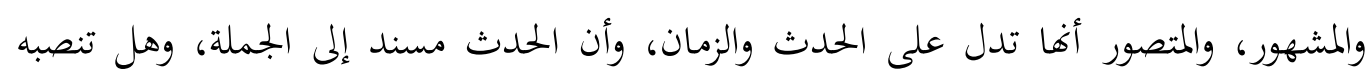
فتقول: كان زيد قائمًا كونًا أجازه بعضهم، وبه قال السيرافي، ومنعه الجمههور، وذهب ابن خروف إلى أها مشتقة من مصادر لم يلفظ بها،

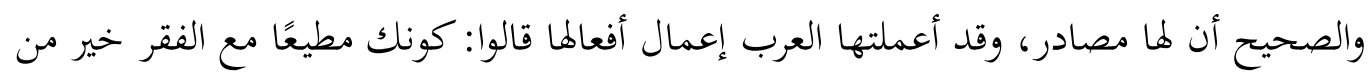

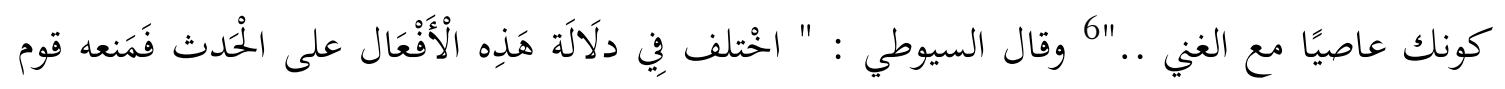

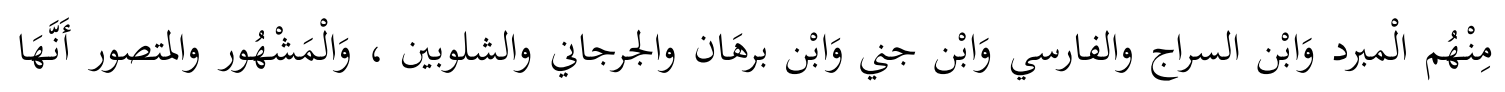

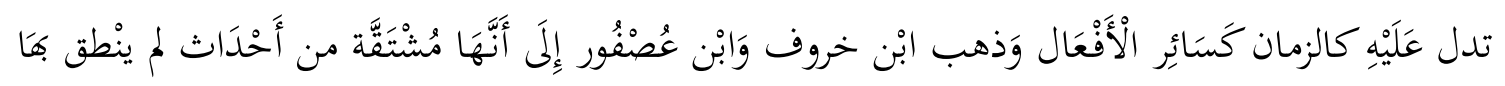
$7 "$

والقول بدلالة هذه الأفعال على الزمن والحدث معا أكده ابن مالك ، وععَّ القول بتجريدها من

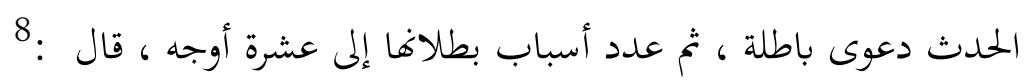

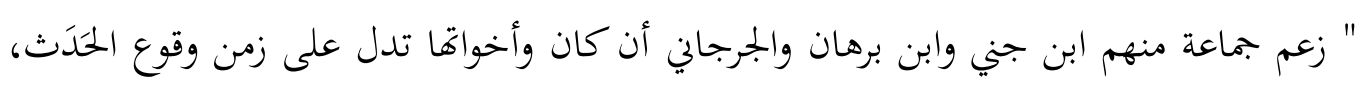

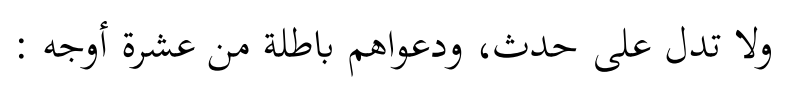

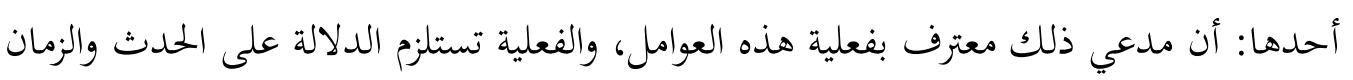

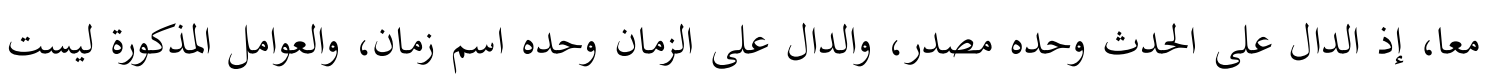
بمصادر ولا أسماء زمان، فبطل كوغا دالة على أحد المعنيين دون الآخر.

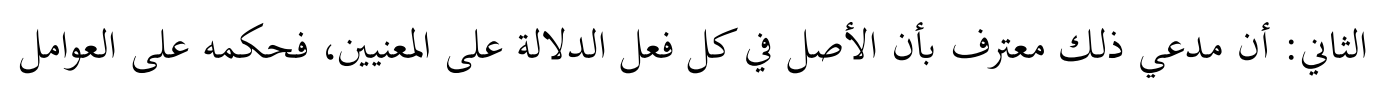
المذكورة بما زعم إخراج لها عن الأصل، فلا يقبل إلا بدليل.

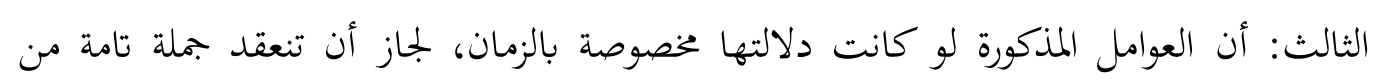

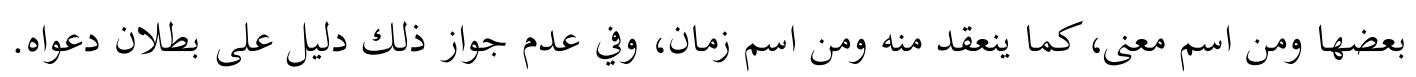

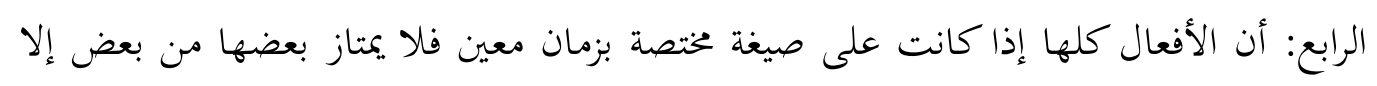

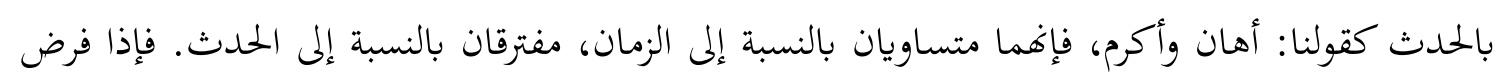

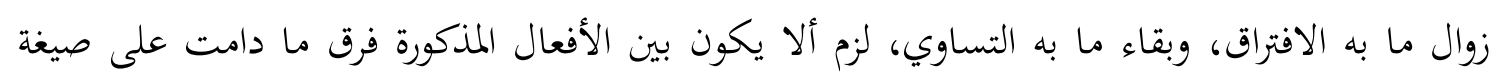

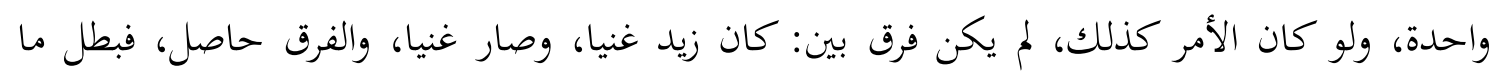

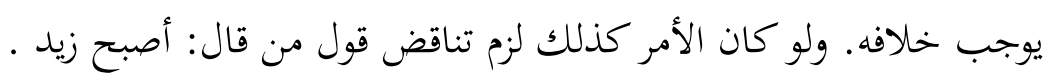


الخامس: أن من جملة العوامل المذكورة انفك، ولا بد معها من ناف، فلو كانت لا تدل على الحدث الذي هو الانفكاك، بل على زمن الخبر، لزم أن يكون معنى: ما انفك زيد غنيا: ما زيد غنيا في وقت من الأوقات الماضية، وذلك نقيض المراد، فوجب بطلان ما أفضى إليه. السادس: أن من جملة العوامل المذكورة دام، ومن شرط إعمالها عمل كان كوها صلة لما المصدرية، ومن لوازم ذلك صحة تقدير المصدر في موضعها، كقولك: جُحْ ما دمت واجدا، أي: جد مدة دوامك واجدا، فلو كانت دام مجردة عن الحدث لم يقم مقامها اسم الحدث. السابع: أن هذه الأفعال لو لم يكن لما مصادر لمُ تدخل عليها أنْ، كقوله تعالى: (إلا أنْ تكونا ملكين) لأنّ أنْ هذه وما وصلت به في تأويل المصدر، وقد جاء مصدرها صريحا في قول الشاعر: ببذلٍ وحِلْم سادَ في قومه الفتى ... وكونُك إياه عليك يسيرُ وقد حكى أبو زيد في كتاب الهمزة مصدر فتئ مستعملا، وحكى غيره: ظللت أفعل كذا ظكلولا. وجاءوا بمصدر كاد في قولم: لا أفعل ذلك ولا كيدا، أي ولا أكاد كيدا، وكاد فعل ناقص من باب كان، إلا أفا أضعف من كان، إذ لا يستعمل لها اسم فاعل، واسم فاعل كان مستعمل، ولا يستعمل منها أمر، والأمر من كان مستعمل، وإذا لم يمتنع استعمال مصدر كاد، وهي أضعف من كان، فأن لا يمتنع استعمال مصدر كان أحق وأولى.

الثامن: أن هذه الأفعال لو كانت لمجرد الزمان لم يغن عنها اسم الفاعل، كما جاء في الحديث: "إن هذا القرآن كائن لكم أجرا، وكائن عليكم وزرا" وقال سيبويه: "قال الخليل: هو كائنُ أخيك على الاستخفاف، والمعنى: كائنٌ أخاك" هذا نصره.

$$
\text { وقال الشاعر: }
$$

وما كلهُ مَنْ يُبْدِي البشاشة كائنا ... أخحاك إذا لمُ تُلْفِه لك مُنْجِدا لأن اسم الفاعل لا دلالة فيه على الزمان، بل هو دال على الحَدث وما هو به قائم، أو ما

$$
\begin{aligned}
& \text { هو عنه صادر. ومثل ذلك } \\
& \text { قول الآخر: }
\end{aligned}
$$

قضى الله يا أسماءُ أنْ لستُ زائلا ... أحِبُّكُك حتى يُغْمِضَ العينَ مُغْمِضُ أراد: لست أزال أحبك، فأعمل اسم الفاعل عمل الفعل.

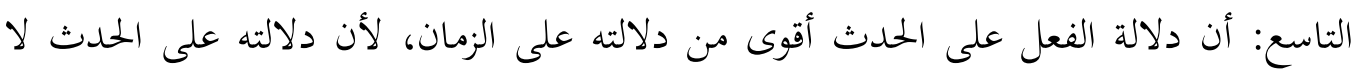
تتغير بقرائن، ودلالته على الزمان تتغير بالقرائن، فدلالته على الحدث أولى بالبقاء من دلالته على الزمان. العاشر: أن هذه الأفعال لو كانت مجردة عن الحدث، مخلصة للزمان لم يُبْن منها أمرن كقوله تعالى: (كونوا قَوّامين بالقسط) لأن الأمر لا يبنى مما لا دلالة فيه على الحدث. وما ذهبت إليه في هذه المسألة من كون هذه الأفعال دالة على مصادرها، هو الظاهر من قول سيبويه والمبرد والسيرافي. وأجاز السيرافي الجمع بين كان ومصدرها توكيدا، ذكر ذلك في شرح الكتاب. 
فإذا ثبت بالدلائل المذكورة أن هذه الأفعال غير دالة على الحدث والزمان كغيرها من الأفعال،

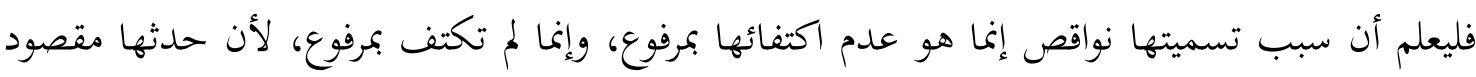

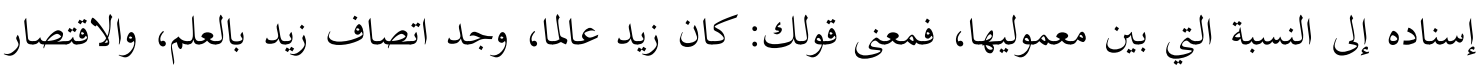

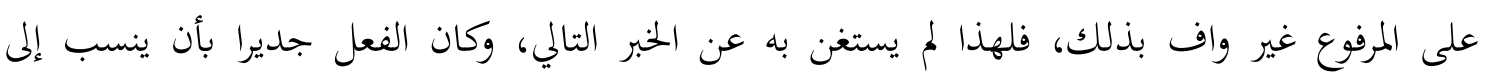
النقصان.

وقد أشار إلى هذا المعنى سيبويه بقوله: "تقول: كان عبد الله أخاك، فإنما أردت أن تخبر عن

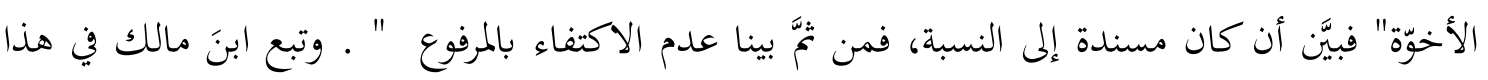
الرأي أبو حيان وابنُ هشام. 9

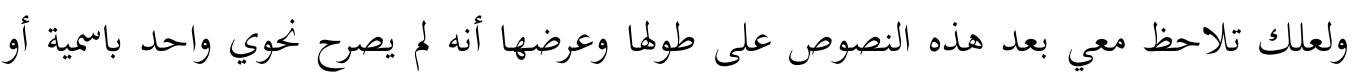

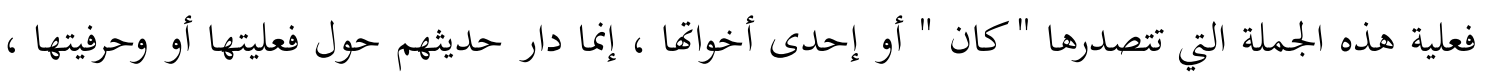

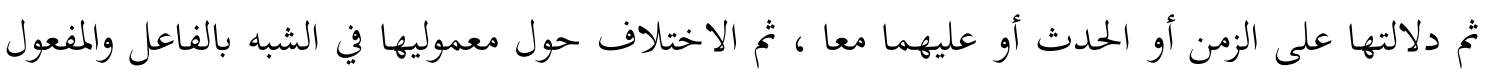

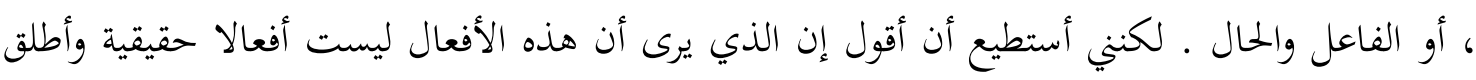

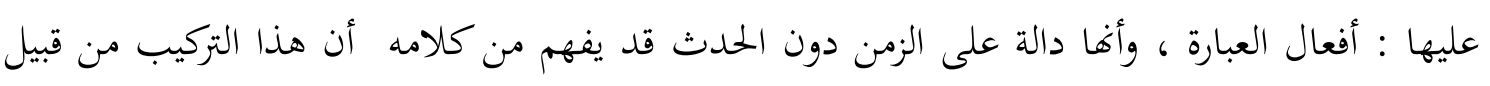

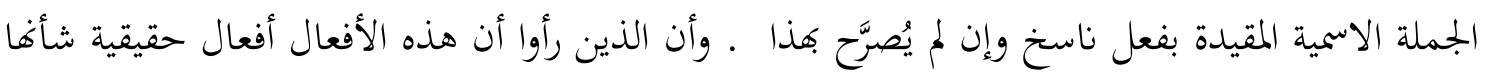

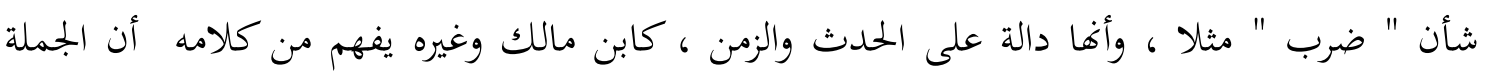
المتصدرة بهذه الأفعال هي جملة فعلية حقيقية .

الأمر الثاني : الذي دفعني - أيضا - إلى التحقيق في هذه المسألة أنني لاحظت ألنأ أن الجملة

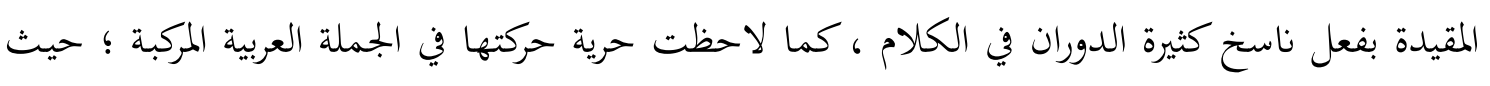
تعددت مواقعها الإعرابية ، فمن أمثلة وقوعها خبرا قوله تعالى : " كل الطعام كان حلا لا لبني إسرائيل 10 ."

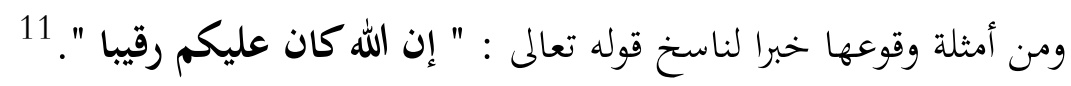

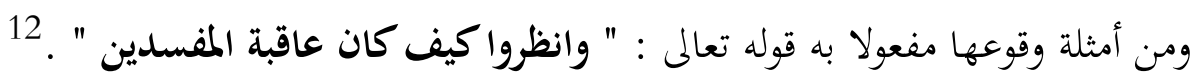

ومن أمثلة وقوعها نعتا قوله تعالى : " ليقضي الله أمراكان مفعولا ". 13

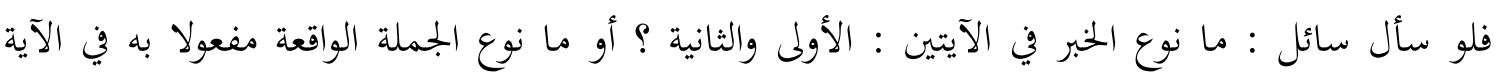
الثالثة ؟

9 ارتثاف الضرب 1151/3، وهمع الهوامع للسيوطي 74/2. 10 سورة آل عمران ، من الآية : 93 .

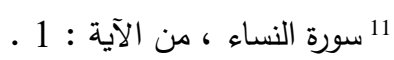

12 سورة الأعراف ، من الآية : 86 .

13 سورة الأنفال ، من الآية : 44 ـ. 
أو ما نوع الجملة المصدرة بفعل ناسخ الواقعة نعتا في الآية الرابعة ؟ هل هي اسمية أم فعلية ؟ كيف يكون

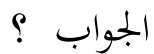

وما الذي يعتمد عليه هذا الجواب ؟ هذا الأمر كان دافعا لي إلى التحقيق في هذه المسألة من خلال آراء النحاة المتقدمين والمتأخرين · والذي لاحظته - على ما قرأت- أنه لم يصرح واحد من النحاة بنوع الجملة

التي تصدرت بهذا

النوع من الناسخ من حيث الاسمية أو الفعلية كما بدا لنا من النصوص التي نقلتها آنفا ، سوى ابن هشام

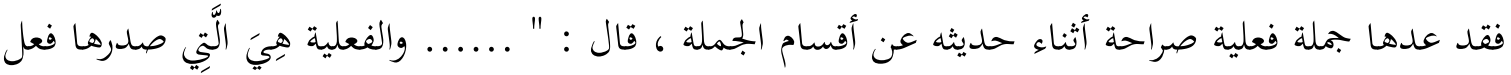

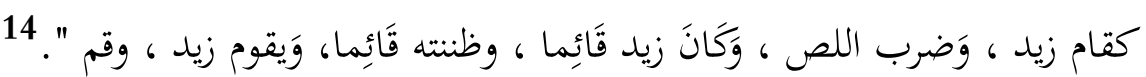
وتعليقا على خلاف النحاة في هذه القضية ، يقول الدكتور / محمد حماسة عبد اللطيف - رحمه

الله - : " والذي أوقع النحاة في هذا الخلاف عدة أسباب هي :

1- أها تتصرف تصرف الأفعال فيصاغ من بعضها المضارع والأمر.

2- أها تلحقها تاء التأنيث الساكنة، وهم يعدون هذه التاء من علامة الفعل وتختص به. 3- أها تلحقها تاء الفاعل وألف الاثنين وواو الجماعة فتقول كنت وكانا وكانوا، كما تقول: قمت وقاما وقاموا وما أشبه ذلك

ومهما يكن من أمر فقد اتفق النحاة على أن هذه الأفعال أفعال غير حقيقية ، ولهذا تسمى أنس أفعال العبارة كما يقول الأنباري، ولو أن النحاة اعترفوا بما يسمى الأدوات المتصرفة ، لما حدث مثل هذا الاضطراب والخلاف.

والمراد بكوها أفعالا غير حقيقية ذكره بن فضال في شرح عيون الإعراب، قال: "ومما يدلك أها ليست أفعالا حقيقية

أن اسم الفاعل واسم المفعول فيه كشيء واحد؛ تقول: كان زيد أخاك ؛ فالأخ زيد في المعنى ، وإذا قلت :

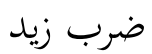
عمرا، فيقال لك: ماذا فعل زيد؟ فتقول: الضرب، ولو قلت: كان زيد أخاك، فقيل لك: ماذا فعل زيد؟ لم يجز أن تقول الكون". 16 وهذا الكالام يخالف ما ذهب إليه ابن مالك ومن لف لفه من كون هذه الأفعال تدل على الزمن والحدث ، فهي لا تعدو - كما ذكر ابن فضال ومن لف لفه - أفعالا غير حقيقة تدل على زمن دون حدث .

وعلى هذا الأساس فقد رجح أستاذنا الدكتور محمد حماسة عبد اللطيف " رحمه الله " أستاذ النحو والصرف والعروض بكلية دار العلوم ، جامعة القاهرة ، وعضو بجمع اللغة العربية ، كون الجملة المكونة من

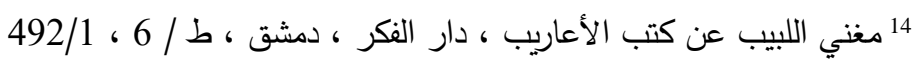

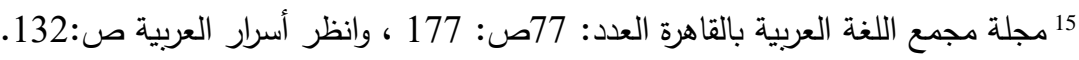
16 شرح عيون الإعراب ط/2 ، مكتبة الآداب ، تحقيق د/ عبد الفتاح سليم ص:105. 
المبتدأ والخبر المصدرة بـ "كان" أو إحدى أخواتها جملة اسمية ، ، ذاكرًا ما برر به هذا الترجيح في ثماني نقاط

17: على النحو التالي

أولا : أن الجملة الاسمية مبهمة الزمان ، ، فإذا قلت : " محمد كريم " ، فأنت تثبت الكرم لحمد مطلقا دون

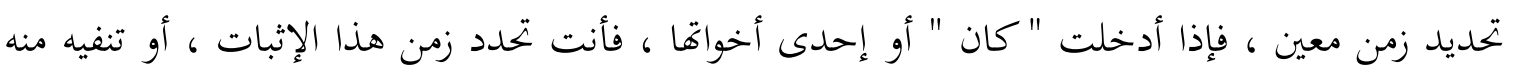

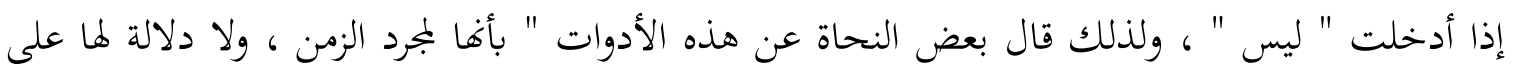

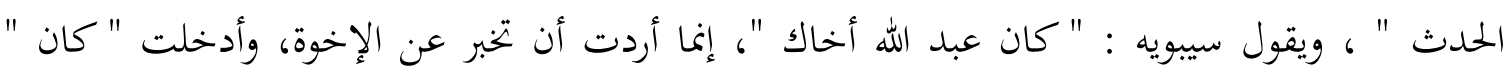

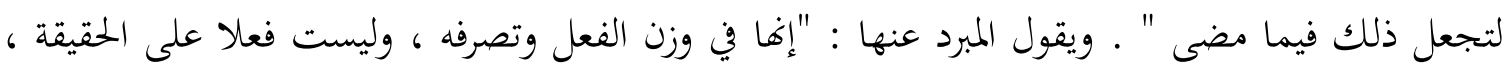

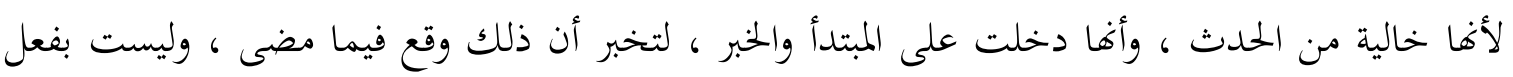
وصل منك إلى غيرك .

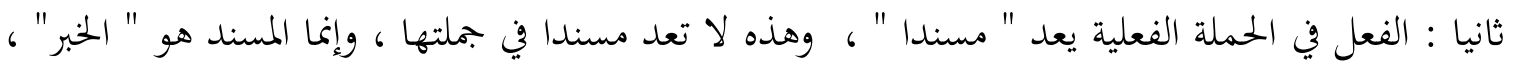

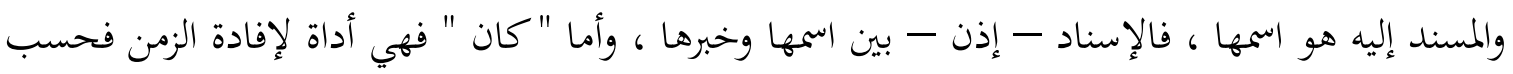
، كما سبقت الإشارة إلى ذلك .

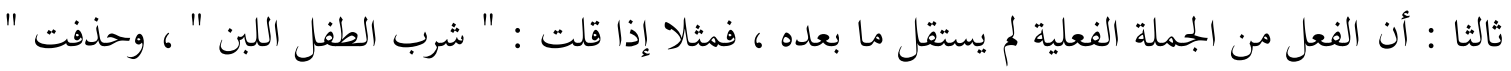

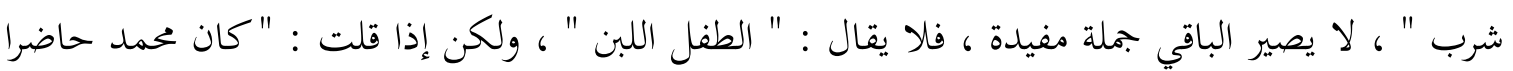

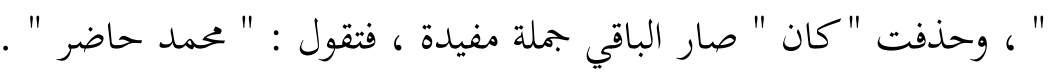

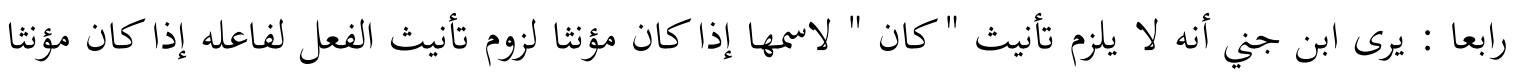

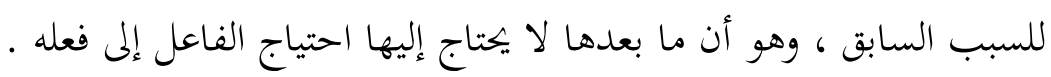

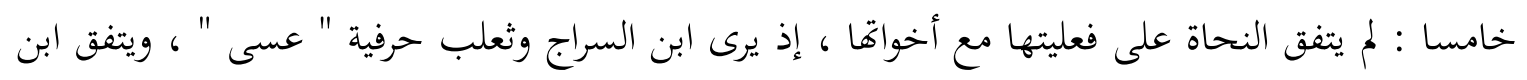

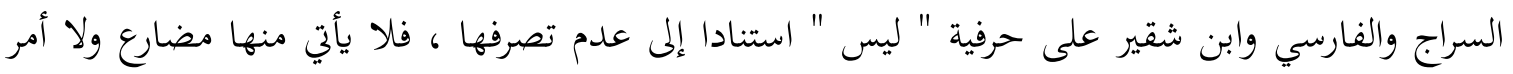

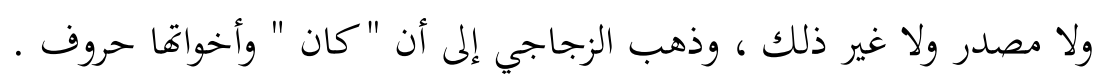

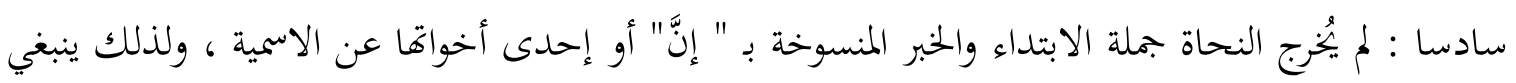

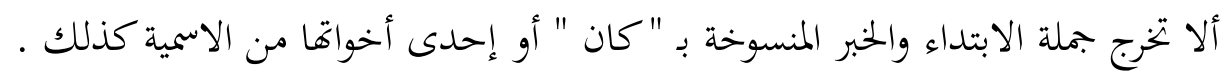

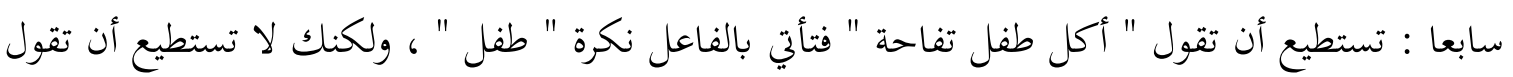

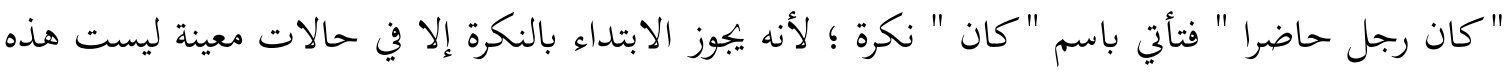

ثامنا : مما يدل على كون "كان وأخواتما " أدوات أها تدخل على الأفعال كما تدخل الأدوات مع أنه " لا

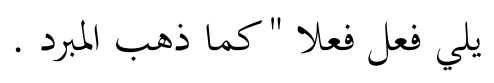

ولذلك عدها بعض الباحثين المحدثين أدوات منقولة من الفعل للدلالة على الزمن في الجملة الاسمية التي تخلو من الدلالة عليه. 
لهذه الأسباب مجتمعة يسوغ لنا أن نعد الجملة المنسوخة بـ " كان " أو إحدى أخواتما من الجملة الاسمية ، كما تعد الجملة المنسوخة بـ " إن " وأخواتما من الجملة الاسمية .

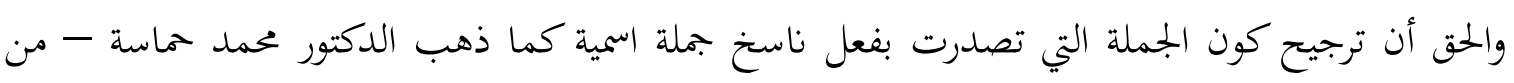
وجهة نظري - له ما يبرره ويقويه فإن وصف " إن " وأخواتا بالنسخ نشأ من تغييرها لحكم الاسم " المبتدأ " من الرفع إلى النصب ، دون أن يمس هذا التغيير كون الجملة اسمية ـ وشأن "كان" وأخواتها في معنى

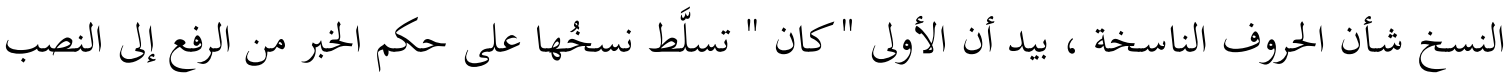
، فمن البديهي أن بتري هذه الأفعال الناسخة بجراها.

وأخيرًا ، فإن تفسير النقص في الأفعال الناسخة - كما عبَّر عنه النحاة- عدم اكتفائها بالمرفوع ، مما يعني أهما أفعال غير حقيقية ، أو بتعبير السيوطي غير صحيحة . فالفعل الحقيقي قد يكتفي بفاعله إذا كان لازما، أقول: قام الرجل ، ونام الطفل .... إلخ. ولا يصح معها هي مثل هذا، فلا يستقيم أن أقول: اليوم الجو بارد ، أما الأمس فكان الجو.... ، دون أن أخبر عن طبيعة الجو بالأمس، فأقول مثلا : حارًا . كذلك فإنه يتسنى لي أن أحذف "كان" في مثل قولي: كان العرب متفرقين، فتصير الجملة: العرب متفرقون. فالملاحظ أن الجملة لم تتغير ماهيتها في وجود "كان" أو عدمه، ولم يتغير سوى الخبر من النصب إلى

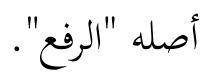

لكن لا يصح حذف "كان" التامة التي خرجت عن نطاق الوصف بالنسخ إلى نطاق فعل آخر بمعنى

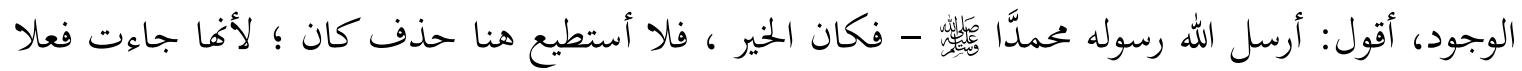

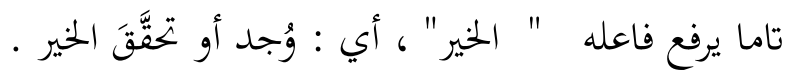
لكن ثمة مشكلة قدٌ تواجهنا في ترجيح وجه الاسمية للجملة المنسوخة بـ "كان " أو إحدى أخواتها تكمن في ورود هذا التركيب في النصوص العربية على أنه تركيب فعلي ، أعني كونه جملة فعلية وليست اسمية ، من هذا توكيد هذه الجملة بـ " قد " أو " لقد " وهي أدوات تختص بتوكيد الجملة الفعلية المبدوءة بفعل ماض ، ومن

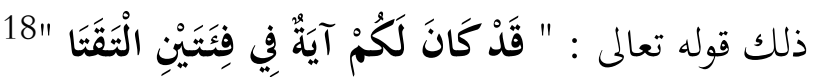

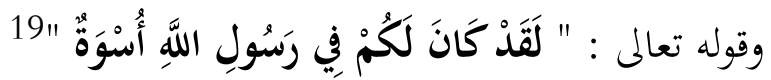
أو وقوع هذا التركيب جوابا لشرط دون الاقتران بالفاء ، لأنه لو كان تركيبا اسميا لوجب اقترانه بالفاء ، من

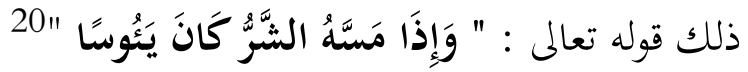
والمخرج من هذا أن الظاهر في مثل هذا التركيب أنه مبدوء بفعل وهو " كان " ، فهو من قبيل الجملة الفعلية ، لكنها جملة فعلية مؤقتة أو طائة " إن صح التعبير " ، أو إن شئت فقل : الجملة الفعلية شكلا وليس معنى ، لأننا عند التحقيق نجد أن هذه الجملة في حقيقتها جملة اسمية مقيدة بناسخ ، أو منسوخة بفعل 
ناسخ ، وهي تتجرد من الفعلية بمجرد خلوها من هذه المقيدات الطارئة ، وليس هذا الشأن في الجملة الفعلية

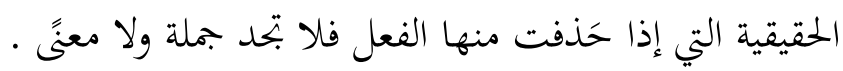

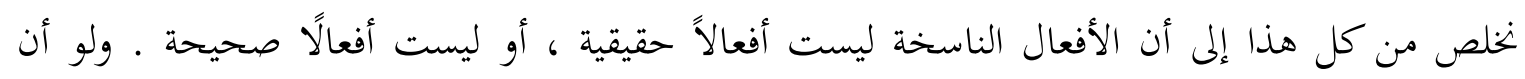

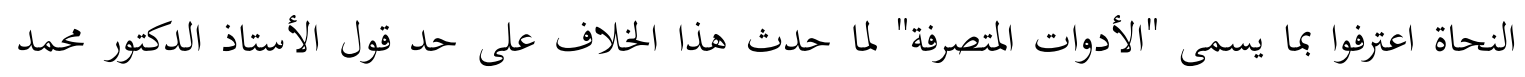

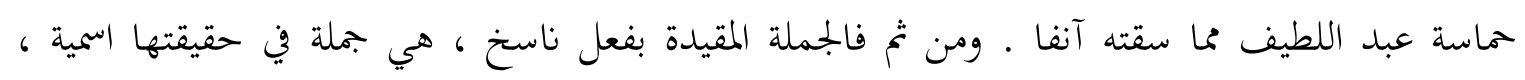

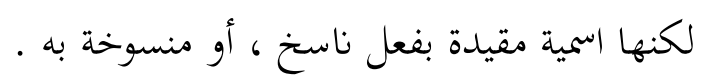

الخاتمة

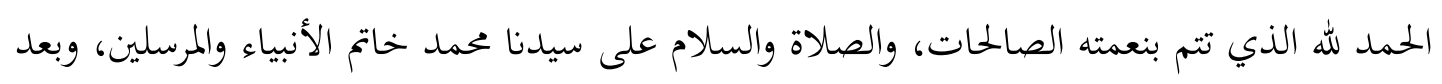

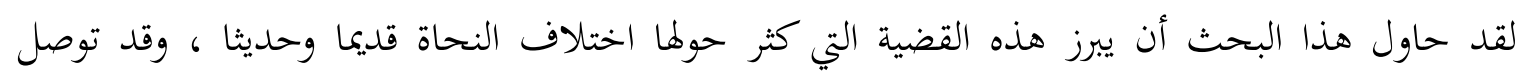

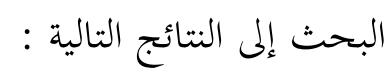
1- أيد البحث رأي من قال من النحاة بكون " كان " وأخواتما ليست أفعالا حقيقية ، أو أها تسمى أفعال العبارة .

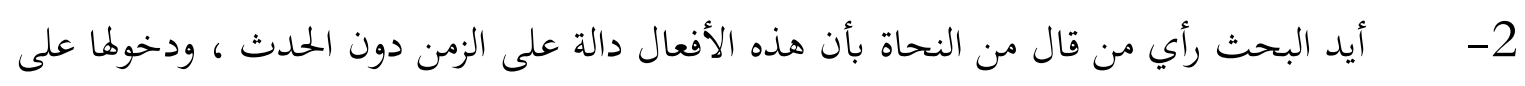

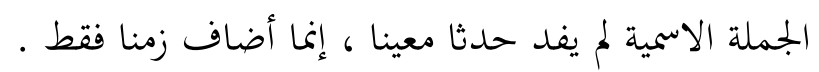

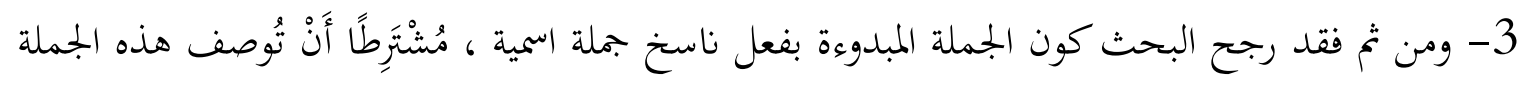

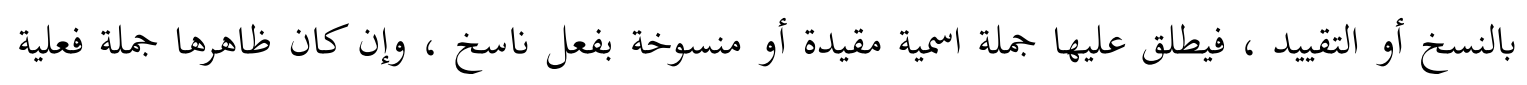

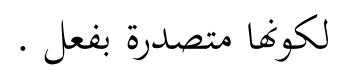




\section{المصادر والمراجع}

أسرار العربية : أبو البركات، كمال الدين الأنباري (المتوف: 577هـ) ، دار الأرقم بن أبي الأرقم ، ط / 1 . ارتشاف الضرب : أبو حيان الأندلسي (المتوفن: 745 هـ) ، مكتبة الخانجي بالقاهرة ، ط / 1 . جامع الدروس العربية : مصطفى بن محمد سليم الغلايينى (المتوف: 1364هـ) ، المكتبة العصرية، صيدا - بيروت ط

شرح ابن عقيل : عبد الله بن عبد الرحمن ابن عقيل (المتوف: 769هـ) ، تحقيق : محمد محيي الدين عبد الحميد ، دار التراث - القاهرة، دار مصر للطباعة ، ط / 20 . شرح التسهيل : جمال الدين محمد بن عبد الله ، ابن مالك (المتوفى 672هـ ) ، تحقيق : د. عبد الرمن السيد، د. محمد بدوي المختون ، هجر للطباعة ، ط/1 .

اللمع في العربية : أبو الفتح عثمان بن جني الموصلي (المتوف: 392هـ) ، تحقيق / فائز فارس ، دار الكتب الثقافية

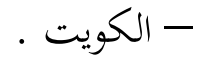
بجلة بجمع اللغة العربية بالقاهرة العدد : 177. مغني اللبيب عن كتب الأعاريب: عبد الله بن يوسف ، أبو محمد ، جمال الدين، ابن هشام (المتوفن: 761هـ) ، دار

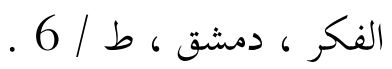
النحو الوافي : عباس حسن (المتوفن: 1398هـ) ، دار المعارف ، ط / 20 . همع الهوامع: عبد الرحمن بن أبي بكر، جلال الدين السيوطي (المتوفن: 911هـ) ، تحقيق : عبد الحميد هنداوي ، المكتبة

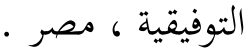




\section{KAYNAKÇA}

'Abu Albarkat, Kamal Aldiyn Al'anbarii (Almutawafaa: 577h). 'Asrar Alearabiat. Dar Al'arqam Bin 'Abi Al'arqam, T/ 1.

'Abu Alfath Euthman Bin Jini Almawsilii (Almutawafaa: 392h). Allamae Fi Alearabiat. Alkuayt Tahqiq/Fayiz Faris, Dar Alkutub Althaqafiat.

'Abu Hian Al'undilsi (Almutawafaa: 745 H). Airtishaf Aldarab. Maktabat Alkhanijii, Bialqahirat, T $/ .1$

Eabbas Hasan (Almtwfa: 1398h). Alnahw Alwafi. Dar Almaearif, T / 20.

Eabd Allh Bin Eabd Alruhmin Abn Eaqil (Almutawafaa: 769h). Sharah Abn Eaqil. Tahqiq:

Muhamad Muhyi Aldiyn Eabd Alhamid, Dar Alturath - Alqahrt, Dar Misr Liltabaeat, T / 20.

Eabd Alruhmin Bin 'Abi Bukr, Jalal Aldiyn Alsayuti (Almutawafaa: 911h). Hamae

Alhwame.Tahqiq: Eabd Alhamid Hindawi. Almaktabat Altawfiqiat, Misr.

Jamal Aldayni, Eabd Allah Bin Yusif, 'Abu Muhamad, Abn Hisham (Almatawafaa: 761h). Maghni Allibayb Ean Kutib Al'aeariba. Dar Alfikr, Dimashq, T /6.

Jamal Aldiyn Muhamad Bin Eabd Allh, Abn Malik (Almutawafaa 672h ). Sharah Altashil, .Tahqiq: Eabd Alruhmin Alsyd, D. Muhamad Badawii Almakhtun, Hijr Liltibaeat, T/1.

Majalat Majmae Allughat Alearabiat Bialqahirat Aleadad: 177.

Mustafaa Bin Muhamad Salim Alghalayinaa (Almtwfa: 1364h). Jamie Aldurus Alearabiat. Almaktabat, Aleisriatu, Saydaan - Bayrut T / 28. 


\section{EXTENDED SUMMARY}

\section{THE SENTENCE THAT BEGINS WITH "KAN" AND ITS SIBLINGS, WHETHER IT SHOULD BE A NOUN PHRASE OR VERB PHRASE}

This research deals with the grammarians 'opinion about the sentence that begins with "kan" and its siblings, is it a nce become verb phrase or remains noun phrase? noun phrase or verb phrase? In another meaning,if we put kan at the beginning of a sentence ,does this sente.

What led me to ask such a question are two opinions .The first one is that modern grammarians differ on whether) kan) is verb or preposition. Most of grammarians agree that kan is a verb but they differ on (lays). The grammarians also differ on whether kan and its siblings express time only or time and event. Farthermore, they differ on marfue and mansub kan. The second reason is that the sentence that begins with "kan" and its siblings is used a lot in Arabic Language in different positions as It can be predicate, object or adverb .' All food was lawful to the Children of Israel ' (Aali 'Imran-93) is an example of being predicate. What type of predicate? Is it noun phrase or verb phrase? What the answers would be if we are asked these questions and on what evidence. All these questions stimulated me to make this research depending on what grammarians said before.

I went on in this research that the grammarians did not declare - as I read - if it is a noun phrase or verb phrase, except Ibn Hisham in his book, "Moghni al Labib" stated that it is a verb phrase .

But the other grammarians differed in the fact that "kan" and its siblings were verbs or preposition, those who said they are verbs, differed in their being indicative of time only or event only or both. Some of the grammarians also went on to say that they are verbs that were not real, and called them verbs of the phrase.

The research stats a view from one of the modern grammarians who said that the sentence which begins with "kan" and its siblings is a noun phrase, namely, Dr. Mohamed Hamasa Abdullatif (may Allah have mercy on him) Professor of grammar and linguistics at the Faculty of Dar Al-Uloum, Cairo University, and member of the Arabic Language Academy, Saying what he relied on in this opinion in eight points. one point is If the verb is omitted from the verb phrase, what comes after will be dependent. For example if we say (The boy drank milk)" shurb alwald allabn" and if the verb (drank)"shrub" is omitted, the sentence will be incorrect. On the other hand ,if we omit kan from this sentence ( the boy was here)" kan alwald hadiran" it will be correct.

ibn Genie believes that it is not necessary to feminize "kan" for its name if it was feminine to the need for feminization of the verb for its subject if it was feminine for the previous reason. That you can say "a child ate an apple" (akl altifl tofaha) we can use the subject without (ال) but we can't say "A man was here" (kana rajul hona) it means we can't use the word "man"( rajul) without (ال) 
because we can't start the sentence with a subject without (ال) except in certain cases, which are not these.

In this research, I believe that the sentence that begins with "kan", is a noun phrase, adding to what Mohammed Hamasa Abdul Latif said, which strengthens this opinion as the verb can settle for its subject. We can say :( qam alrajul, wanam altifl) 'the man stood up.....the child has slept'.It is not correct to say: Today is cold, but yesterday was .., without completing the sentence, say, for example: warm. 